Paper ID.: 8125

\title{
Operational Conditions in a W-Clad Tokamak
}

R. Neu, Ch. Hopf, A. Kallenbach, T. Pütterich, R. Dux, H. Greuner, O. Gruber, A. Herrmann, K. Krieger, H. Maier, V. Rohde and the ASDEX Upgrade Team

MPI für Plasmaphysik, Boltzmannstr. 2. D85748 Garching, Germany

Key word codes: C0600, T1000, P0500, D0500, F0400

Experiments with tungsten plasma facing components (PFCs) are performed in the ASDEX Upgrade divertor tokamak and the area covered by W-PFCs has been increased steadily since 1999 reaching $85 \%$ for the 2005/2006 campaign. The configurations chosen are $\mathrm{W}$ coatings on graphite and CFC. The different locations are subject to different power loads and erosion yields. This is taken into account by selecting different thicknesses in the $\mathrm{W}$-coating manufactured either by physical vapour deposition or vacuum plasma spraying. Power loads in excess of 15 $\mathrm{MW} / \mathrm{m}^{2}$ can be handled in this way. The experiments on ASDEX Upgrade show that plasma operation is feasible with walls and divertor surfaces mostly covered with tungsten, but also reveal critical issues: Fast particles from plasma heating can play a crucial role in $\mathrm{W}$ erosion and particle transport must be kept high enough to overcome high impurity content and to prevent central impurity accumulation.

\section{Introduction}

Economic fusion power production will critically depend on the availability of plasma-facing components (PFCs) which offer plasma compatibility, low erosion, small and controllable tritium inventory, good heat exchange properties and stability under neutron irradiation. PFCs in present day devices are mostly designed to optimise fusion performance, partially neglecting the technical needs of a future fusion power plant. Even the next step device, ITER [1], follows a conservative approach using beryllium for the main chamber PFCs in order to minimise the risk of high power loss through impurity radiation in the central plasma. In a reactor however, Be will not be a viable solution due to its high erosion yield and high- $Z$ components may have to be used $[2]$.

Experiments with PFCs are performed in the ASDEX Upgrade divertor tokamak to explore the feasibility of using tungsten as plasma facing material. The area covered by W-PFCs has been 
increased steadily since 1999 reaching $85 \%$ for the 2005/2006 campaign. The configurations chosen are $\mathrm{W}$ coatings on graphite and CFC (carbon fibre reinforced carbon). The different components are subject to different power loads and erosion yields. This is taken into account by selecting appropriate different thicknesses of the $\mathrm{W}$-coatings produced either by physical vapour deposition (PVD) or vacuum plasma spraying (VPS). This paper presents experiences from the use of W coatings as PFCs and results on the influence of tungsten on plasma operation.

\section{Rationales for the use of $W$ coatings and results on their performance}

Most present day fusion devices use graphite or CFC as plasma facing material (PFM) due to their good thermo-mechanical properties, good machineability, and the benign behaviour of carbon as an impurity in plasma discharges. Additionally, these materials have a lower electrical conductivity than metals. This property keeps eddy currents and halo currents low and prevents arcing due to electrostatic charging. In contrast, tungsten has a conductivity $\quad(\sigma=$ $\left.2 \cdot 10^{7} \Omega^{-1} \mathrm{~m}^{-1}\right) 200$ times as large as carbon based materials and its mass density $\left(19.3 \mathrm{~g} \mathrm{~cm}^{-3}\right)$ is larger by a factor of 8.5 . These properties would lead to a considerable higher load on the support structures if bulk tungsten tiles were used. Although the higher forces would be technologically manageable (see for example the ITER divertor design [1]), they would make the transition from a device designed for C-based PFCs very costly and time consuming. Therefore ASDEX Upgrade has chosen the coating solution. In preparatory experiments using markers [36], the erosion at different positions of the PFCs has been evaluated and the thickness and the technique for coating were chosen accordingly. In 1995 [7], and again from 2000 onward [8] the $\mathrm{W}$ coatings were qualified and tested. Thin coatings $(<10 \mu \mathrm{m})$ were reliably produced on graphite using physical vapour deposition (PVD) techniques. These thin coatings withstood power loads of more than $15 \mathrm{MW} / \mathrm{m}^{2}$ up to melting conditions and showed very good adhesion when produced by plasma arc deposition [9]. They even survived thermal shocks using an ion beam with power loads above $30 \mathrm{MW} / \mathrm{m}^{2}$ for $0.3 \mathrm{~s}$. Tungsten coatings on graphite (SGL Carbon R6710) were more reliable than on CFC (Dunlop DMS 704), which can be attributed to the very inhomogeneous surface characteristics and the strong mismatch of thermal expansion coefficients resulting from fibre orientation of the CFC. In cases where thicker coatings are required, a transition to other techniques was necessary since delamination of sputter-PVD layers occurred for thickness $>3 \mu \mathrm{m}$ [9] or cracks developed [7]. In the case of ASDEX Upgrade, vacuum plasma sprayed (VPS) tungsten deposited on a Re/W PVD multilayer (produced by Plansee/Sulzer Metco) was employed successfully in the tungsten divertor experiment in 1996 [10]. VPS coatings with a thickness of $200 \mu \mathrm{m}$ on graphite SGL Carbon R6710 were produced by Plansee, similar to the ones successfully tested and reported in [11] for use at areas of high erosion in ASDEX Upgrade (low field side poloidal limiters, lower divertor). During the most recent campaign $(2004 / 2005)$ thin $(3 \mu \mathrm{m})$ PVD coatings and VPS coatings were tested at similar positions on the low field side poloidal limiters. The thin coatings survived operation with power loads of several $\mathrm{MW} / \mathrm{m}^{2}$ measured by $2 \mathrm{D}$-thermography without any damage, whereas the thick 
coatings show extensive melting. Post mortem investigation by optical microscopy and SEM revealed that delamination occurred at or in the PVD interlayer, leading to poor thermal contact and subsequent melting of the VPS layer. Laboratory experiments are underway to clarify the damage mechanism and to develop thick coatings which can be reliably used in regions with high power load and enhanced erosion.

\section{Transition to a $\mathbf{W}$ clad device}

Since 1999 ASDEX Upgrade steadily converted from a complete carbon device to one with nearly full $\mathrm{W}$ coverage [12]. On the occasion of a maintenance vent in 2002 all W coated tiles were replaced by new W PFCs. The further stages of the W programme are marked by colours in the poloidal cross section shown in Fig. 1 and further details are given in table 1. The sequential procedure allowed integrating the construction work into the annual repair and upgrading works. Simultaneously, the influence of certain PFCs on the plasma performance (for example operating with $\mathrm{C}$ or $\mathrm{W}$ divertor [13]) and mixed material effects could be studied [5]. However, carbon is still present in the machine and in the plasma discharges, which could influence the results of the operation with tungsten due to surface layers, edge cooling and $\mathrm{W}$ sputtering by impact of $\mathrm{C}$ ions. However, a survey of the W PFCs in the main chamber performed after the end of the 2005 campaign revealed that only very minor amounts of $\mathrm{C}$ are present in co-deposited layers. This can be deduced from Fig. 2, where the columns give the minimum and maximum relative amount of the elemental composition for 5 poloidal positions. The values were obtained from nuclear reaction analysis (NRA) using a $2.5 \mathrm{MeV}^{3} \mathrm{He}$ beam. The absolute layer density of the co-deposited layer varies from $\sim 1 \times 10^{18} \mathrm{at} / \mathrm{cm}^{2}$ to $\sim 8 \times 10^{18} \mathrm{at} / \mathrm{cm}^{2}$. More details of this surface analysis will be published in a forthcoming publication [17]. Oxygen results from residual water which could not be completely desorbed by the baking procedure and from small vacuum leaks. Boron as main contributor can be explained by the surface conditioning with regularly performed glow discharge boronisations. The ${ }^{13} \mathrm{C}$ layers result from a dedicated puff experiment carried out prior to opening of the machine.

\section{Conclusions from the operation with W PFCs in ASDEX Upgrade}

\subsection{Erosion Mechanisms}

Low-Z impurities not only lead to deposited layers in areas with low power load, but also dominate the sputtering yield of $\mathrm{W}$ under normal operating conditions. They typically reach the plasma facing components with an ion charge of $Z=2$ to $Z=4$, because they cannot recombine completely during their transport towards the plasma edge. Therefore, they gain the additional energy of $3 \mathrm{ZkT}_{\mathrm{e}}$ in the plasma sheath. The sputtering threshold energy for deuterium on tungsten 
is about $210 \mathrm{eV}$ [18] and consequently purely thermal background ions do not contribute significantly to the yield. However, in the main chamber hotter ions and fast particles from charge exchange and auxiliary heating can contribute to the $\mathrm{W}$ erosion. The measured erosion flux at the low field side limiters in ASDEX Upgrade can only be explained by taking into account the impact of fast deuterons from neutral beam injection (NBI) and the acceleration of thermal particles in the rectified sheath in the case of ion cyclotron resonance heating (ICRH) $[14,15]$. In this context it is important to recognize that the power loads introduced by fast particles lead to relatively lower erosion compared to particles with energies at $1 \mathrm{keV}$. This is demonstrated in Fig. 3 showing the W yield per impinging deuteron (left scale) and the flux density of eroded $\mathrm{W}$ atoms for a given power flux density deposited by deuterium particles of a given energy.

\subsection{Influence of W PFCs on plasma behaviour}

Besides the problematic erosion and deposition behaviour of low-Z PFMs and especially of C, plasma operation benefits from the strong radiative edge cooling of low- $Z$ impurities. To sustain this effect it might become necessary to substitute the missing radiation in a carbon free device by artificially introduced impurities such as noble gases as shown in [19]. In the present ASDEX Upgrade operation the $\mathrm{C}$ content in the plasma discharges is reduced only marginally. This is attributed to strong recycling of $\mathrm{C}$, which leads to a large gross $\mathrm{C}$ influx despite of only very small amounts of $\mathrm{C}$ in the top surface layer. Nevertheless, the strong depletion of $\mathrm{C}$ in codeposited layers (see Sec. 3) explains the gradual increase of the divertor electron temperature. Fig. $4 \mathrm{~b}$ ) shows the long term evolution of the electron temperature at the inner divertor strikepoint deduced from thermo-current measurements as a function of discharge number. As stated in Sec. 2, melting of W coatings occurred at the low field side ICRH limiter and a considerable part of the campaign was run with the damaged limiter. From this it can be concluded that melting of $\mathrm{W}$ does not inevitably lead to an interruption of the experimental program.

The major drawback of $\mathrm{W}$ as a plasma facing material is its potential for deterioration of plasma performance and confinement. Not only does tungsten radiate strongly at temperatures ambient in the core of a fusion plasma but neoclassical transport also favours central accumulation of high-Z elements. These facts require a thorough investigation of the behaviour of $\mathrm{W}$ in plasma discharges. Comparing the $\mathrm{W}$ concentrations measured in the edge and in the centre of the plasma shows that the concentrations profiles can be strongly peaked (up to a factor of 60, see [13]) pointing to the dominant effect of central transport. Additionally, a strong suppression of the edge transport (as in ELM-free H-Mode) can lead to an increased W density over the whole plasma radius $[13,16]$. The central accumulation can be suppressed by increasing the anomalous transport using central wave heating. Triggering edge instabilities (so called ELM pace-making) and thereby increasing the average impurity transport at the edge leads to a reduction of the $\mathrm{W}$ concentration over the whole plasma radius. The tungsten concentration generally increases with 
the area of the W coating in ASDEX Upgrade (see upper part of Fig.4), but the effect is nonlinear and such other experimental parameters as the scrape-off layer (SOL) impurity composition, edge temperature, and surface layers are important as well. The SOL temperature is particularly important since it strongly affects the $\mathrm{W}$ sputtering yield and - as can be judged from Fig.4 - the highest W concentrations around \#19000 correlate with the divertor temperature.

\subsection{Consequences for ASDEX Upgrade and future devices}

The experiments at ASDEX Upgrade indicate that plasma operation is feasible with walls and divertor surfaces mostly covered with tungsten, but also reveal critical technical and plasma physical issues. In order to eliminate $\mathrm{C}$ as far as possible from the surfaces and the plasma, a complete transition to $\mathrm{W}$ coated surfaces is envisaged for next year.

Although the use of coatings will not be directly transferable to the highly power loaded components of a reactor, it considerably reduces the efforts, without jeopardising scientific significance. A similar procedure is envisaged for the JET 'ITER-like wall project' when converting the CFC- to a W-divertor [20]. Additionally, VPS W-coatings - although on steel would have sufficient erosion lifetime as main chamber PFCs in a reactor. Mock-ups made of steel and covered with $2 \mathrm{~mm} \mathrm{~W}$-VPS were successfully tested with steady state heat loads up to 2.5 $\mathrm{MW} / \mathrm{m}^{2}$ [21]. In its present configuration the ASDEX Upgrade design strongly resembles the ITER design for the PFCs, particularly with respect to the concept of a carbon free main chamber wall. Extrapolations to a complete $\mathrm{W}$ wall in ITER suggest [16] that the central W concentration could be sufficiently low at the price of somewhat reduced performance as a consequence of the above mentioned mitigation techniques.

\section{References}

[1] R. Aymar, P. Barabaschi, Y. Shimomura, Y, Plasma Phys. Control. Fusion 44 (2002) 519

[2] H. Bolt, V. Barabash, G. Federici, J. Linke, A. Loarte, J. Roth, K. Sato, J. Nucl. Mater. 307-311 (2002) 43

[3] D. Naujoks, J. Roth, K. Krieger, G. Lieder, M. Laux, J. Nucl. Mater. 210 (1994) 43

[4] K. Krieger, H. Maier, R. Neu, ASDEX Upgrade Team, J. Nucl. Mater. 266-269 (1999) 207

[5] K. Krieger, J. Likonen, M. Mayer, R. Pugno, V. Rohde, E. Vainonen-Ahlgren, ASDEX Upgrade Team, J. Nucl. Mater. 337-339 (2005) 10

[6] H. Maier, J. Nucl. Mater. 335 (2004) 515

[7] C. García-Rosales, S. Deschka, W. Hohenauer, R. Duwe, E. Gauthier, J. Linke, M. Lochter, W.K.W.M. Mallener, L. Plöchl, P. Rödhammer, A. Salito, ASDEX Upgrade Team, Fus. Technol. 32 (1997) 263 
[8] H. Maier, J. Luthin, M. Balden, S. Lindig, J. Linke, V. Rohde, H. Bolt, ASDEX Upgrade Team, J. Nucl. Mater. 307 - 311 (2002) 116

[9] H. Maier, J. Luthin, M. Balden, M. Rehm, F. Koch, H. Bolt, Surf. Coat. Technol. 142144 (2001) 733

[10] R. Neu, K. Asmussen, S. Deschka, A. Thoma, M. Bessenrodt-Weberpals, R. Dux, W. Engelhardt, J. C. Fuchs, J. Gaffert, C. García-Rosales, A. Herrmann, K. Krieger, F. Mast, J. Roth, V. Rohde, M. Weinlich, U. Wenzel, ASDEX Upgrade Team, ASDEX NI-Team, J. Nucl. Mater. 241-243 (1997)

[11] X. Liu, S. Tamura, K. Tokunaga, N. Yoshida, N. Noda, L. Yang, Z. Xu, J. Nucl. Mater. 329-333 (2004) 687

[12] R. Neu, R. Dux, A. Geier, O. Gruber, A. Kallenbach, K. Krieger, H. Maier, R. Pugno, V. Rohde, S. Schweizer, ASDEX Upgrade Team, Fus. Eng. Des. 65 (2003) 367

[13] R. Neu, R. Dux, A. Kallenbach, T. Pütterich, M. Balden, J.C. Fuchs, A. Herrmann, C.F. Maggi, M. O'Mullane, R. Pugno, I. Radivojevic, V. Rohde, A.C.C. Sips, W.Suttrop, A. Whiteford, ASDEX Upgrade Team, Nucl. Fusion 45 (2005) 209

[14] R. Dux, A. Herrmann, A. Kallenbach, R. Neu, J. Neuhauser, H. Maier, R. Pugno, T. Pütterich, V. Rohde, ASDEX Upgrade Team, J. Nucl. Mater., 337-339 (2005) 852

[15] R. Dux, V. Bobkov, A. Kallenbach, K. Krieger, R. Neu, T. Pütterich, V. Petrizilka, V. Rohde, J. Stober, ASDEX Upgrade Team, EPS Conf. on PPCF,'Tungsten erosion at auxiliary limiters in ASDEX Upgrade', EPS Geneva, ed.: C. Hidalgo and B.Ph. van Milligen, vol. 29C, P1.010, Tarragona, 2005

[16] A. Kallenbach, R. Neu, and R. Dux, H.U. Fahrbach, J.C. Fuchs, L. Giannone, O. Gruber, A. Herrmann, P.T. Lang, B. Lipschultz, C.F Maggi, J. Neuhauser, V. Philipps, T. Pütterich, V. Rohde, J. Roth, G. Sergienko, A.C.C. Sips, A. ASDEX Upgrade Team., Plasma Phys. Control. Fusion 47 (2005) 207

[17] Ch. Hopf, V. Rohde, W. Jacob, A. Herrmann, R. Neu, J. Roth, ASDEX Upgrade Team, 'Oxygen glow discharge cleaning in ASDEX Upgrade', to appear in J. Nucl. Mater. (2007)

[18] W. Eckstein, C. García-Rosales, J. Roth, W. Ottenberger, 'Sputtering data', Report IPP 9/82, IPP Garching, 1993

[19] A. Kallenbach, P.T. Lang, R. Dux, C. Fuchs, A. Herrmann, H. Meister, V. Mertens, R. Neu, T. Pütterich, T. Zehetbauer and the ASDEX Upgrade Team, J. Nucl. Mater. 337339 (2005) 732

[20] G. Piazza, G.F. Matthews, J. Pamela, H. Altmann, J.P. Coad, T. Hirai, A. Lioure, H. Maier, Ph. Mertens, V. Philipps, V. Riccardo, M. Rubel, E. Villedieu, Collaborators of the JET ITER-like Project, 'The JET ITER-like Wall Project', this conference [21] H. Greuner, H. Bolt, B. Böswirth, S. Lindig, W. Kühnlein, T. Huber, K. Sato and S. Suzuki, Fus. Eng. Des. $75-79$ (2005) 333 
Table 1: Recent stages of the tungsten programme at ASDEX Upgrade. For the campaign 2006/2007 a complete W coverage of all PFCs is planned.

\begin{tabular}{|c|c|c|c|c|c|}
\hline Campaign & Location (incremental) & Coating & Area & Remark & References \\
\hline $2002 / 2003$ & $\begin{array}{l}\text { central column } \\
\text { upper PSL } \\
\text { inner baffle low. divertor }\end{array}$ & PVD $1 \mu \mathrm{m}$ & $14.6 \mathrm{~m}^{2}$ & $\begin{array}{l}\text { all new W coatings, } \\
\text { erosion measurements } \\
\text { at central column }\end{array}$ & [12] \\
\hline $2003 / 2004$ & $\begin{array}{l}\text { upper divertor } \\
\text { outer baffle low. Divertor } \\
1 \text { guard limiter }\end{array}$ & PVD $4 \mu \mathrm{m}$ & $24.8 \mathrm{~m}^{2}$ & $\begin{array}{l}\text { test of guard limiters, } \\
\text { erosion measurements } \\
\text { at limiter und divertor }\end{array}$ & {$[13,14,5]$} \\
\hline $2004 / 2005$ & $\begin{array}{l}\text { upper aux. limiter } \\
\text { horiz. plate low. divertor } \\
1 \text { ICRH limiter }\end{array}$ & $\begin{array}{l}\text { PVD } 4 \mu \mathrm{m} \\
\text { VPS } 200 \mu \mathrm{m}\end{array}$ & $28.0 \mathrm{~m}^{2}$ & $\begin{array}{l}\text { test of VPS coatings for } \\
\text { limiter and divertor } \\
\text { applications }\end{array}$ & {$[15,16]$} \\
\hline $2005 / 2006$ & $\begin{array}{l}\text { all poloidal LFS limiters } \\
\text { roof baffle } \\
\text { lower PSL }\end{array}$ & PVD $3 \mu \mathrm{m}$ & $35.9 \mathrm{~m}^{2}$ & $\begin{array}{l}\text { VPS coatings removed, } \\
\text { laboratory tests to find } \\
\text { reliable VPS coatings }\end{array}$ & \\
\hline $\begin{array}{l}\text { 2006/2007 } \\
\text { (planned) }\end{array}$ & $\begin{array}{l}\text { lower Divertor } \\
\text { all toroidal LFS limiters } \\
\text { diagnostic armours }\end{array}$ & $\begin{array}{l}\text { VPS } 200 \mu \mathrm{m} \\
\text { PVD } 3 \mu \mathrm{m} \\
\text { PVD } 3 \mu \mathrm{m}\end{array}$ & $40.8 \mathrm{~m}^{2}$ & $\begin{array}{l}\text { complete W coverage } \\
\text { of all PFCs }\end{array}$ & \\
\hline
\end{tabular}




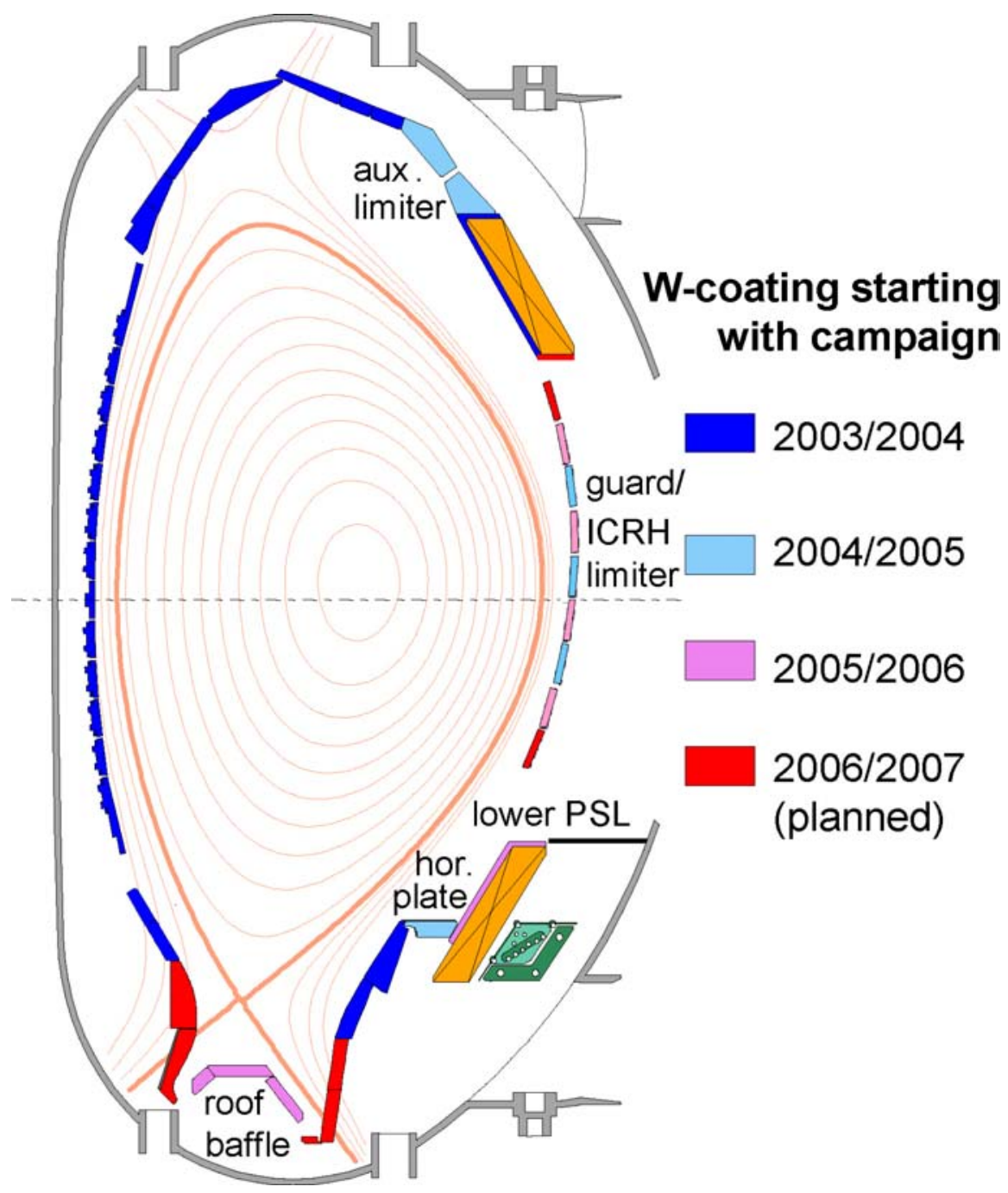

Figure 1: Poloidal cross section of ASDEX Upgrade with colour coded PFCs representing the time of implementation of $\mathrm{W}$ coated tiles. 


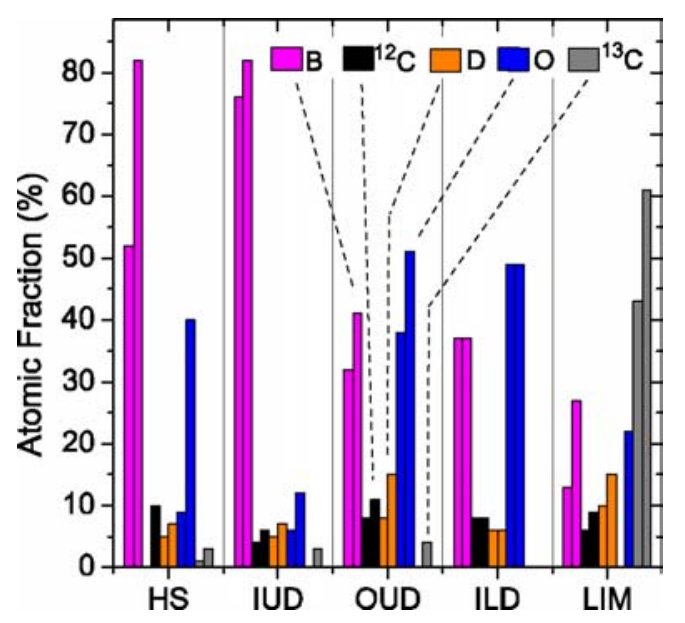

Fig.2: Composition of deposited layers (from NRA with ${ }^{3} \mathrm{He}$ ) on tungsten at different poloidal positions within ASDEX Upgrade. The colour of the columns denotes the different elements/isotopes and the minimum and the maximum value for the fraction is represented by the left and the right column respectively. The positions of the measurement are (HS: central column (heat shield), IUD: inner upper divertor, OUD: outer upper divertor, ILD: baffle inner lower divertor, LIM: low field side guard limiter). 


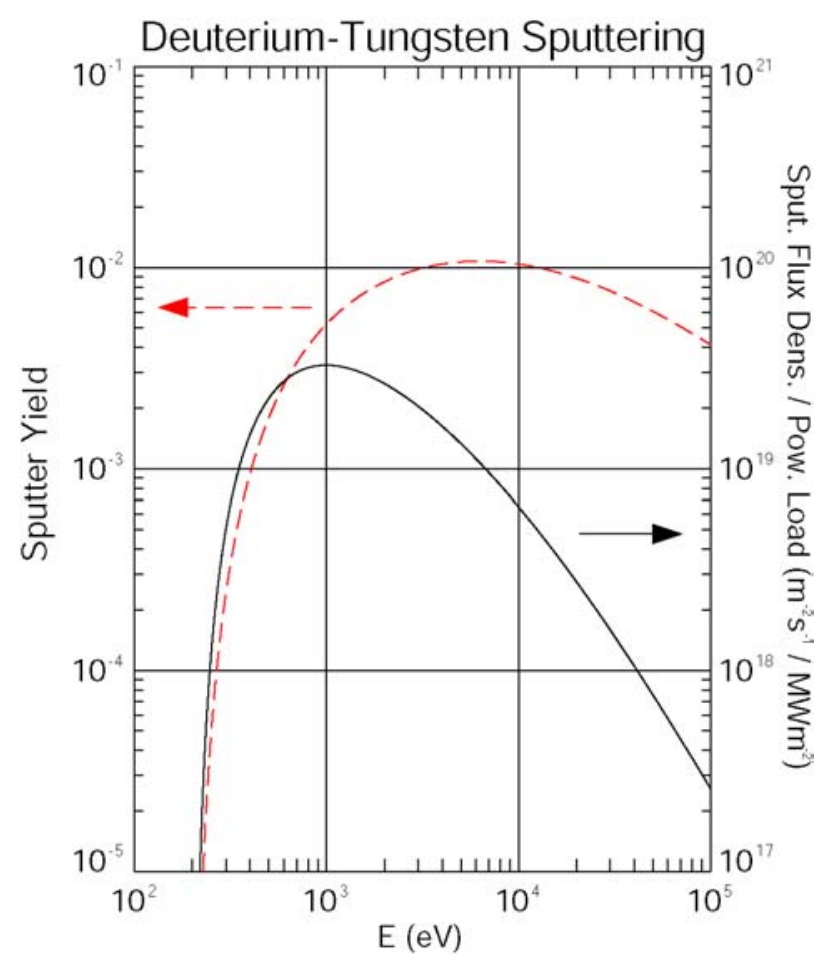

Fig. 3: W erosion flux density / $\mathrm{D}$ power flux density over $\mathrm{E}_{\mathrm{D}}$. The value gives the eroded number of $\mathrm{W}$ atoms for a given power flux deposited by deuterium particles of a given energy. 

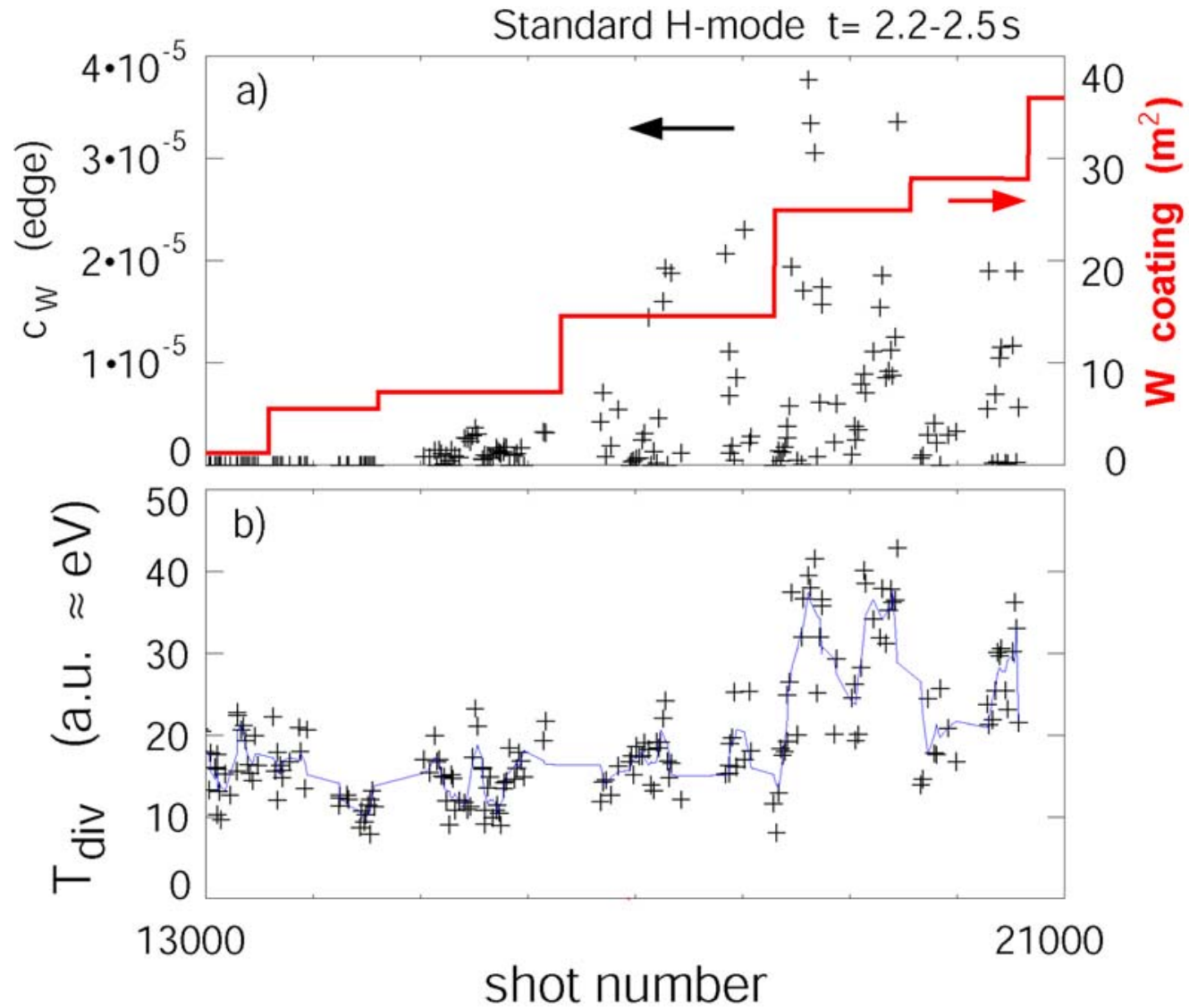

Fig.4: a) W surface coverage in ASDEX Upgrade (right) and W edge concentration (left) and b) divertor plasma temperature deduced from thermo currents in Standard H-Mode discharges averaged from $2.2-2.5 \mathrm{~s}$. 